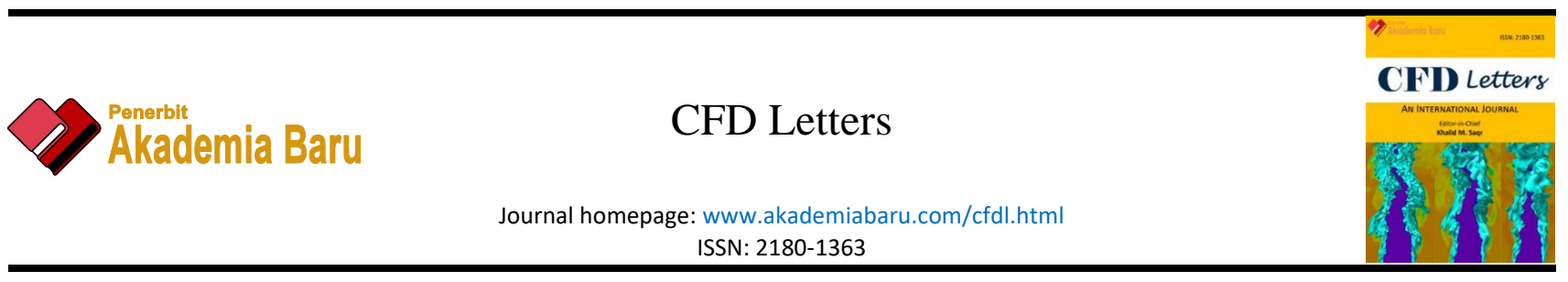

\title{
Numerical Investigation of Mathematical Non-Dimensional Constant Representing Smoothness in the Nusselt Profile
}

\author{
Emaad Ansari ${ }^{1}$, Umair Siddique ${ }^{2}$, Sher Afghan Khan ${ }^{3}$, Mohammad Nishat Akhtar ${ }^{1}$, Elmi Abu Bakar ${ }^{1, *}$ \\ School of Aerospace Engineering, Universiti Sains Malaysia, 14300 Nibong Tebal, Penang, Malaysia \\ Department of Mechanical Engineering, University of Pretoria, 0002, Pretoria, South Africa \\ Department of Mechanical Engineering, International Islamic University Malaysia, 53100, Kuala Lumpur, Malaysia
}

\section{ARTICLE INFO}

\section{Article history:}

Received 19 April 2020

Received in revised form 17 June 2020

Accepted 23 June 2020

Available online 29 June 2020

\section{ABSTRACT}

Cooling of devices using air-jet and other fluid impingement has acquired pace in the manufacturing and electronic device industries. The cooling of the surface using liquid jets is studied using the Nusselt distribution profile. The pattern of the Nusselt profile becomes non-uniform when some parameters are wrongly selected. This may lead to heating of some locations instead of cooling of the surface. Thus research for keeping the Nusselt profile uniform is a primary task. The Nusselt profile depends mainly on the Reynolds number (Re) and nozzle-target spacing ( $\mathrm{Z} / \mathrm{d}$ ). Therefore, the current study numerically evaluates the value of constant, which is a ratio of Reynolds number and nozzle-target spacing $(C=\operatorname{Re} /(\mathrm{Z} / \mathrm{d}))$ up to which the Nusselt profile remains uniform. The value of constant $C$ is found to be 7400 . Also, the present work uses a computational model for study, which is validated using grid independence test and turbulence modeling.

Keywords:

Nusselt profile; Reynolds number; nozzle-target spacing
Copyright @ 2020 PENERBIT AKADEMIA BARU - All rights reserved

\section{Introduction}

Heat transfer distribution using air-jet and other fluid jet is gaining space in industries due to the high heat transfer rate using sprays. The heat transfer rate is dependent on the convective heat transfer coefficient, and the heat transfer coefficient is predicted in terms of Nusselt number. The Nusselt profile gives a better idea about the characteristics of heat transfer. Due to changes in the parameters such as Reynolds number and non-dimensional nozzle-target spacing ( $\mathrm{Z} / \mathrm{d})$, the Nusselt profile changes abruptly and becomes non-uniform, which leads to localized heating at some location and will raise the temperature of the surface at some points. Thus, the study of uniformity of the Nusselt profile is necessary for better performance of jet and better cooling.

\footnotetext{
* Corresponding author.

E-mail address: meelmi@usm.my (Elmi Abu Bakar)
} 


\subsection{Literature Overview}

Umair and Gulhane [1] conducted experiments and simulations to find out the constant that represents the occurrence of the secondary peak in the Nusselt profile curve. Parameters such as Reynolds number and $\mathrm{Z} / \mathrm{d}$ ratio were varied and concluded that for air-jet impingement, this constant values to 6000 .

Simulations were performed by Umair and Gulhane [2] numerically to study heat transfer augmentation from pin fin heat sink. This study made use of laterally impinging air jet to find suitable grid size and turbulence model.

Umair and Gulhane [3] used different materials to study the non-uniformity in their heat transfer characteristics. It was concluded that the Nusselt magnitude increases significantly with a decrease in thermal diffusivity of materials. Also, the non-uniformity wipes out of the Nusselt profile above $66.76 \mathrm{~mm}^{2} / \mathrm{s}$ thermal diffusivities, which is found out to be the critical range.

Umair et al., [4] studied variation in the Nusselt pattern due to the change in geometric thickness $(t / d)$. Simulations were carried out to find out the critical range below which the non-uniformity is visible in the Nusselt profile. This significant range was found out to be 0.05 .

The numerical investigation was carried out by Umair et al., [5] to evaluate the local Nusselt profile between flat plate surface and impinging air jet. The study included a straight, circular nozzle, and it also generated power laws. Semi-empirical relations were constructed for Nusselt number using parameters such as Reynolds number, $\mathrm{Z} / \mathrm{d}$ ratio, Prandtl number $(\mathrm{Pr})$, and $\mathrm{t} / \mathrm{d}$ ratio. The work takes the initiative in defining the semi-empirical relation below the critical value of $\operatorname{Pr} * t / d=0.012$.

The secondary peaks occur in the Nusselt profile for a particular significant range, which was numerically investigated by Umair et al., [6]. The critical range, which is a product of Reynolds number and $\mathrm{Z} / \mathrm{d}$ ratio, was evaluated to be between 2205 and 2646000.

A similar study was carried out by Umair et al., [7] for developing semi-empirical relations for Nusselt number of a pin fin heat sink. Semi-empirical relations of local Nusselt magnitude were obtained as a function of Spacing of fin (S/dp), Height of the fin $(\mathrm{H} / \mathrm{dp})$, Reynolds number, and $\mathrm{Z} / \mathrm{d}$ ratio. Four sets of relations were proposed, which are used to evaluate the local Nusselt magnitude without experiments and simulations.

Semi-empirical relationships of the Nusselt scale were examined by Umair et al., [8] at the lower nozzle target spacing. Reynolds number bears a positive exponent, while the $\mathrm{Z} / \mathrm{d}$ ratio has a negative exponent. The range of negative powers of $\mathrm{Z} / \mathrm{d}$ varies from 0.0025 to 0.38 , while that of positive powers of Reynolds number changes from 0.4 to 0.76 .

Also, the numerical investigation was carried out by Umair et al., [9] for analyzing heat transfer augmentation of pin fin heat sink with the help of a pulse jet. A new dimensionless number is proposed in this work, which characterizes the heat transfer rate. Thus, Umair et al., [1-9] made use of various parameters such as Reynolds number, nozzle-target spacing, Prandtl number, the nondimensional thickness of the plate, and material properties to analyze deeply about heat transfer impingement due to steady air jet.

Khan et al., [10] analyzed threaded spikes numerically and found that it has no side effects on the flow field and is efficient in base pressure control of bodies. Khan et al., [11] created a semi-circular grooved cavity and concluded that it is a very effective passive control mechanism for base pressure regulations. Pathan et al., [12] studied the effect of variations in base pressure on internal and external suddenly expanded flows and found that a similar flow field is formed in internal and external expansion. Pathan et al., [13] researched the effectiveness of nozzle pressure ratio (NPR) and evaluated that with better NPR, base pressure gets reduced. Muhammed et al., [14] focussed on the flow field around a non-circular cylinder and conclude that the pressure drag coefficient is in the 
range of 1 to 1.42. The convergent-divergent nozzle was studied for different area ratios by Khan et al., and Akhtar et al., [15-18]. It was found that the area ratio plays a vital role in base pressure distribution. Yuling et al., [19], Katti and Prabhu [20], Miao et al., [21] and Dahbia and Amina [22] used air jet impingement for cooling of hot surface. Siddique et al., [23] investigated the Nusselt profile for air-jet impingement as well as Siddique et al., [24-25] studied Nusselt profile for water jet impingement.

\subsection{Objectives of the Paper}

Previous research has primarily focussed on the applications and importance of jet impingement techniques, but the constant representing non-uniformity in the Nusselt profile is reported and validated to a very less extent. The evaluation of constant will help in a better selection of parameters, which may eventually lead to better cooling of surfaces. The present study aims at evaluating the value of constant (C), which is a ratio of Reynolds number (Re) and nozzle-target spacing ( $Z / d)$ above which the local Nusselt magnitude profile becomes non-uniform. Also, the present work aims to design a computational model for accurate prediction of results. The computational model will be validated using a grid independence study and turbulence modeling.

\section{Computational Methodology}

Figure 1 shows the computational model of the setup. A 2-D axis-symmetric model is designed in ANSYS CFX solver, having a surface length of $50 \mathrm{~mm}$ and $5 \mathrm{~mm}$ thickness. The model consists of two domains, namely a solid domain and a fluid domain. The setup consists of a nozzle of $7.35 \mathrm{~mm}$ diameter of length $L$ at a distance $Z$ from the target surface. The distance of the nozzle inlet to the target surface is $L 1$. The target length is $L 2$. Heat flux of $1500 \mathrm{~W} / \mathrm{m}^{2}$ is applied at the base of the target surface. The air jet after coming out of nozzle travels through distance $Z$ and impinges on the target surface. After impingement, the air spreads across plate along with radial distance $r$, thereby carrying away the heat of plate and cooling the target surface.

\subsection{Grid Independence Study}

Figure 2 shows the Nusselt profile against the ratio of radial distance to the diameter of the nozzle $(\mathrm{r} / \mathrm{d})$ at various grids having varying growth rates. The grids are having a growth rate of $1.2,1.15,1.1$, $1.05,1.025$, and 1.01. The local Nusselt magnitude at growth rate 1.025 is similar to Nusselt quantity at growth rate 1.01 (Figure 2). Thus, the more fine mesh would produce the same results. Thus, an independent grid is obtained at a growth rate of 1.025. Therefore, further simulations are carried at a growth rate of 1.025 . 


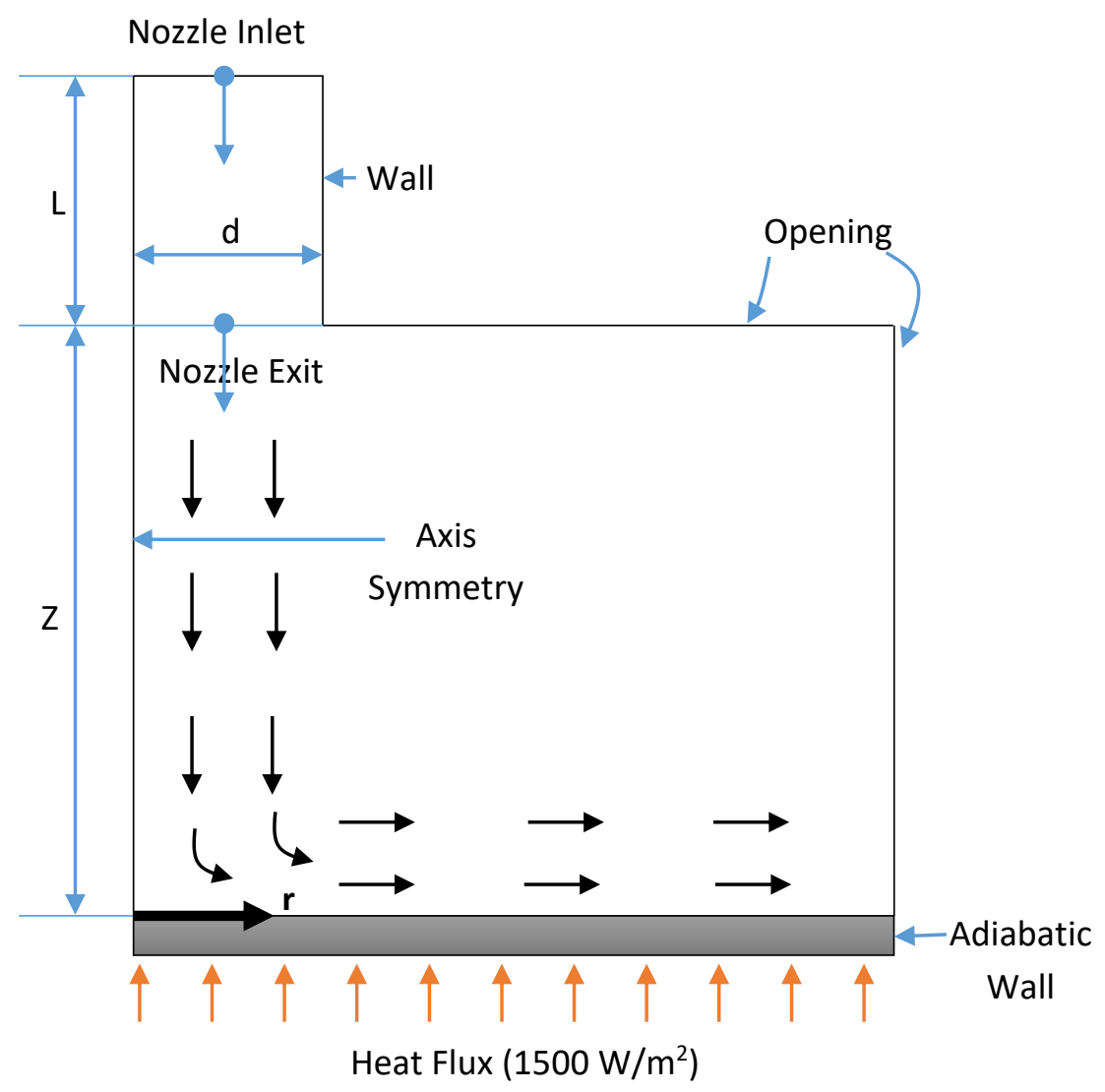

Fig. 1. Schematic layout of the computational model

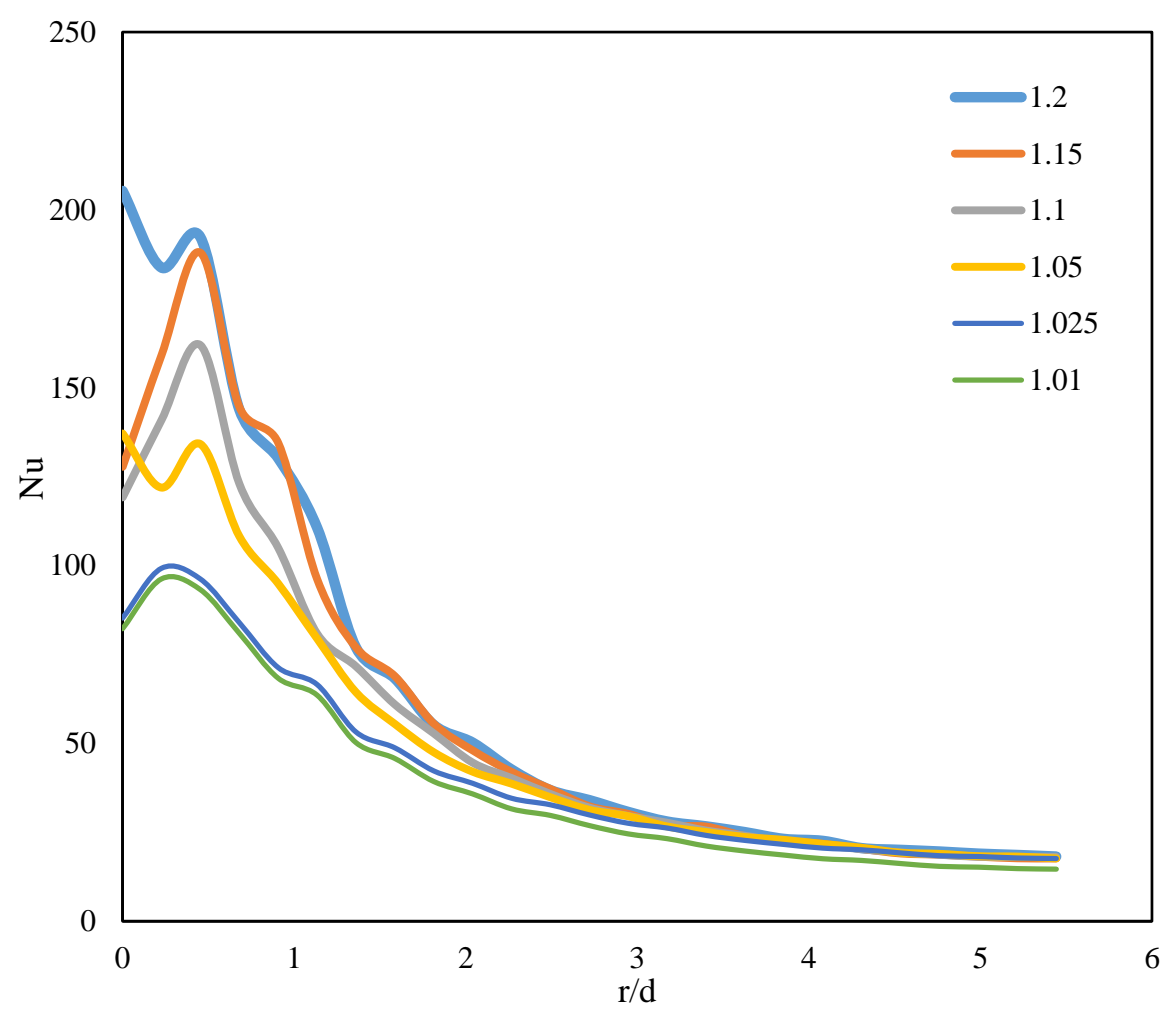

Fig. 2. Grid independence study for various growth rate of 1.2, 1.15, 1.1, $1.05,1.025$ and $1.01 ; \mathrm{Z} / \mathrm{d}=4, \mathrm{Re}=6000$ 
Figure 3 shows the computational model meshing at various growth rates used in the study. The mesh is made fine from coarse one by varying the growth rate from 1.2 to 1.01 . The Nusselt magnitude achieves independence at a growth rate of 1.025 , as seen in Figure 2 . Thus, a fine triangular mesh of growth rate 1.025 is used for the numerical investigation.

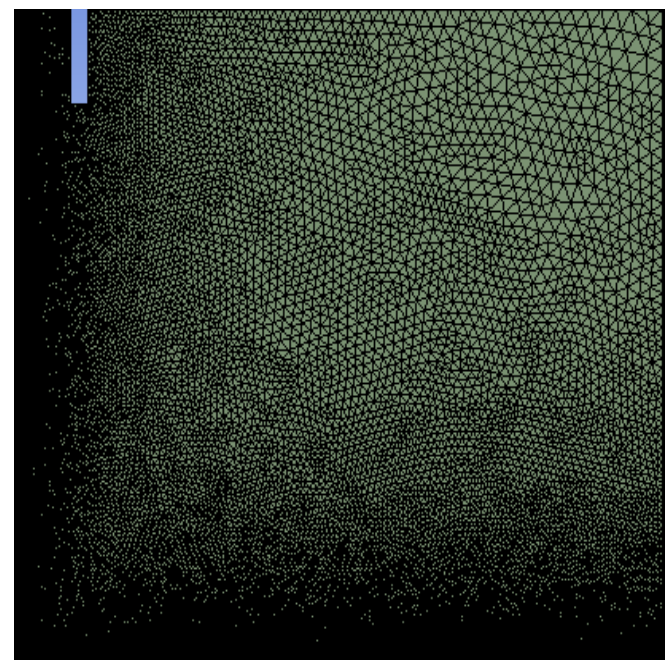

(a) Growth rate $=1.025$

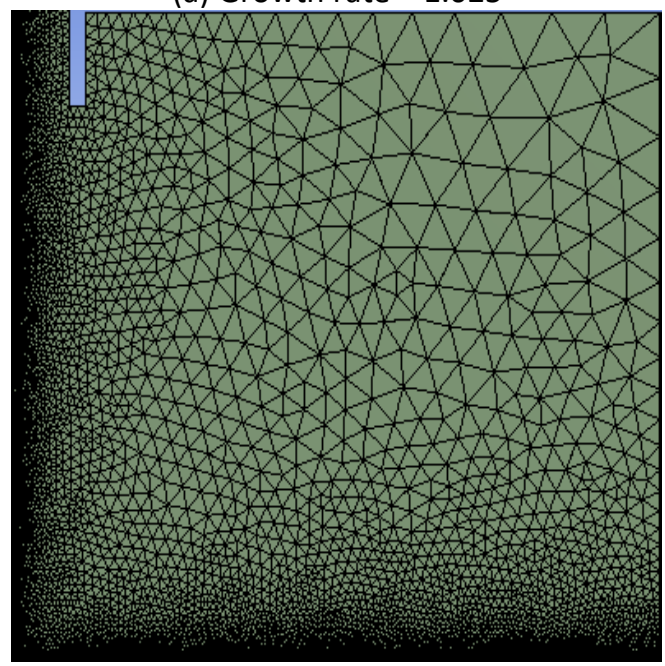

(c) Growth rate $=1.1$

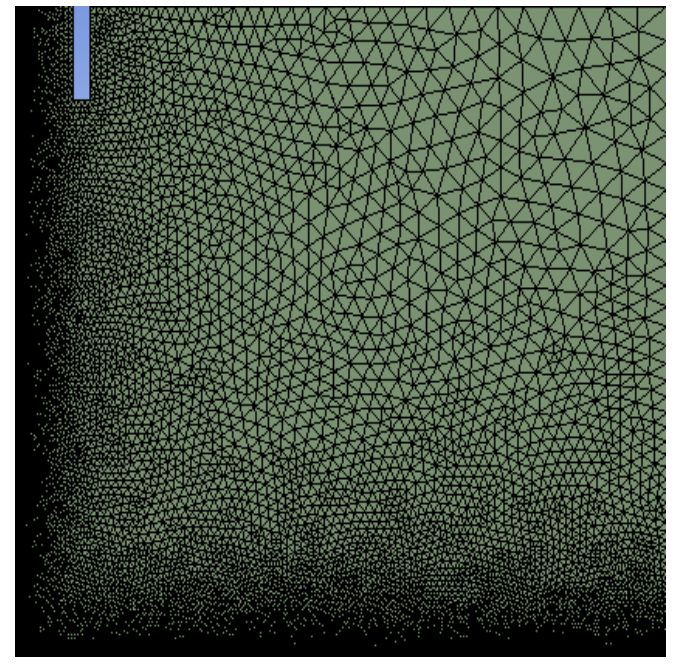

(b) Growth rate $=1.05$

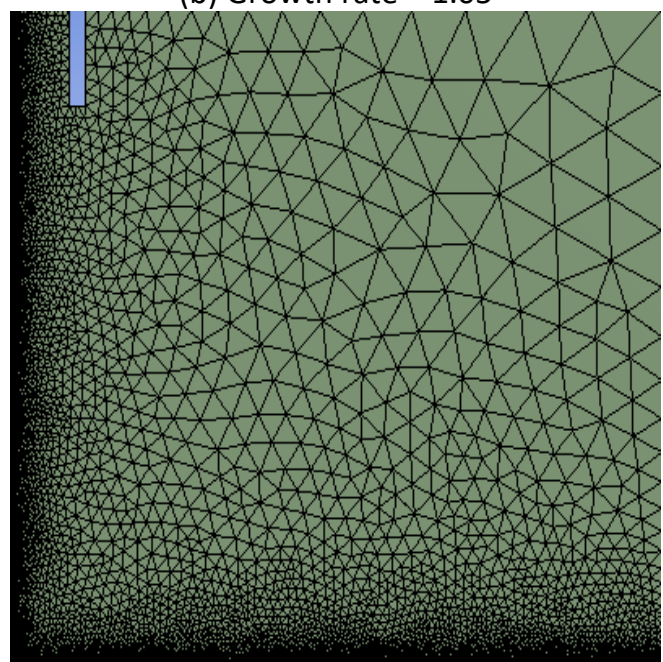

(d) Growth rate $=1.125$

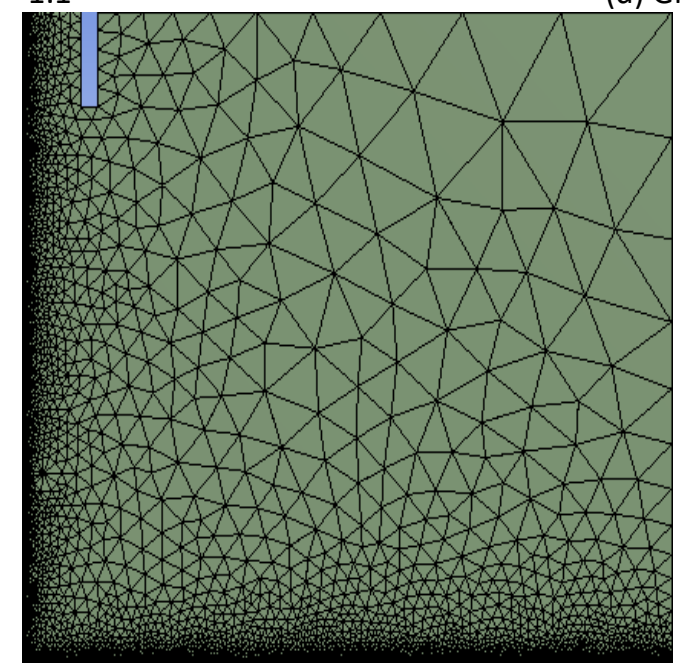

(e) Growth rate $=1.2$

Fig. 3. The computational grid at the various growth rate 


\subsection{Turbulence Modelling}

Eq. (1) and Eq. (2) shows the SST equation which uses $\left(1-F_{t}\right)$ term to reduce fluctuations. Also Eq. (3) and Eq. (4) show the Gamma and Theta equation, respectively, which induces the proper effect of intermediacy and onset transition.

$\frac{\partial(\rho K)}{\partial t}+\frac{\partial\left(\rho U_{j} K\right)}{\partial x_{j}}=\frac{\partial}{\partial x_{j}}\left\{\left[\mu+\sigma_{k} \mu_{t}\right] \frac{\partial K}{\partial x_{j}}\right\}+P_{k}-\beta \rho K \omega$

$\frac{\partial(\rho \omega)}{\partial t}+\frac{\partial\left(\rho U_{j} \omega\right)}{\partial x_{j}}=\frac{\partial}{\partial x_{j}}\left\{\left[\mu+\frac{\mu_{t}}{\sigma_{\omega}}\right] \frac{\partial \omega}{\partial x_{j}}\right\}+2\left(1-F_{t}\right) \rho \frac{1}{\rho_{\omega 2}} \frac{\partial K}{\partial x_{j}} \frac{\partial \omega}{\partial x_{j}}+\alpha_{3} \frac{\omega}{K} P_{k}-\beta \omega \rho^{2}$

Where, $\mathrm{K}$ - Kinetic energy

$\rho$ - Density of fluid

$\mathrm{U}-$ Velocity component in the corresponding direction

$\mu_{t}-$ Eddy viscosity

$\frac{\partial(\rho \gamma)}{\partial t}+\frac{\partial\left(\rho U_{j} \gamma\right)}{\partial x_{j}}=\frac{\partial}{\partial x_{j}}\left\{\left[\mu+\frac{\mu_{t}}{\rho}\right] \frac{\partial \gamma}{\partial x_{j}}\right\}+P_{k}-E_{\gamma}$

$\frac{\partial\left(\rho R e_{\theta t}\right)}{\partial t}+\frac{\partial\left(\rho U R e_{\theta t}\right)}{\partial x_{j}}=\frac{\partial}{\partial x_{j}}\left\{\sigma_{\theta t}\left(\mu+\mu_{t}\right) \frac{\partial R e_{\theta}}{\partial x_{j}}\right\}+P_{\theta t}$

Where, $P_{k}-$ Turbulence production

$E_{\gamma}$ - Dissipation

$P_{\theta t}-$ Controls the flow in the boundary layer

The solver makes use of the continuity equation in Eq. (5) and momentum equation in Eq. (6) along with energy equations for accurately predicting the heat transfer phenomenon.

$\frac{\partial \rho}{\partial t}+\nabla(\rho \cdot \vec{v})=S_{m}$

$\frac{\partial \vec{v}}{\partial t}+\nabla(\rho \cdot \vec{v} \cdot \vec{v})=-\Delta p+\Delta \overline{\bar{\tau}}+\rho \cdot \vec{g}+\vec{f}$

Where $\Delta p$ - Change in pressure

$\Delta \overline{\bar{\tau}}-$ Change in shear stress

Figure 4 shows the Nusselt profile at $\operatorname{Re}=6000$ and $\mathrm{Z} / \mathrm{d}=4$ for different turbulent models. The models are validated with experimental results. The local Nusselt magnitude at various $\mathrm{r} / \mathrm{d}$ ratios evaluated using SST + Gamma-Theta turbulence model is the nearest to experimental values since it captures the turbulence behavior in the near jet region and far jet region along with reducing fluctuations and inducing effect of intermediacy and onset transition. Thus, the SST + Gamma-Theta model predicts the most accurate results among the different turbulence models. 


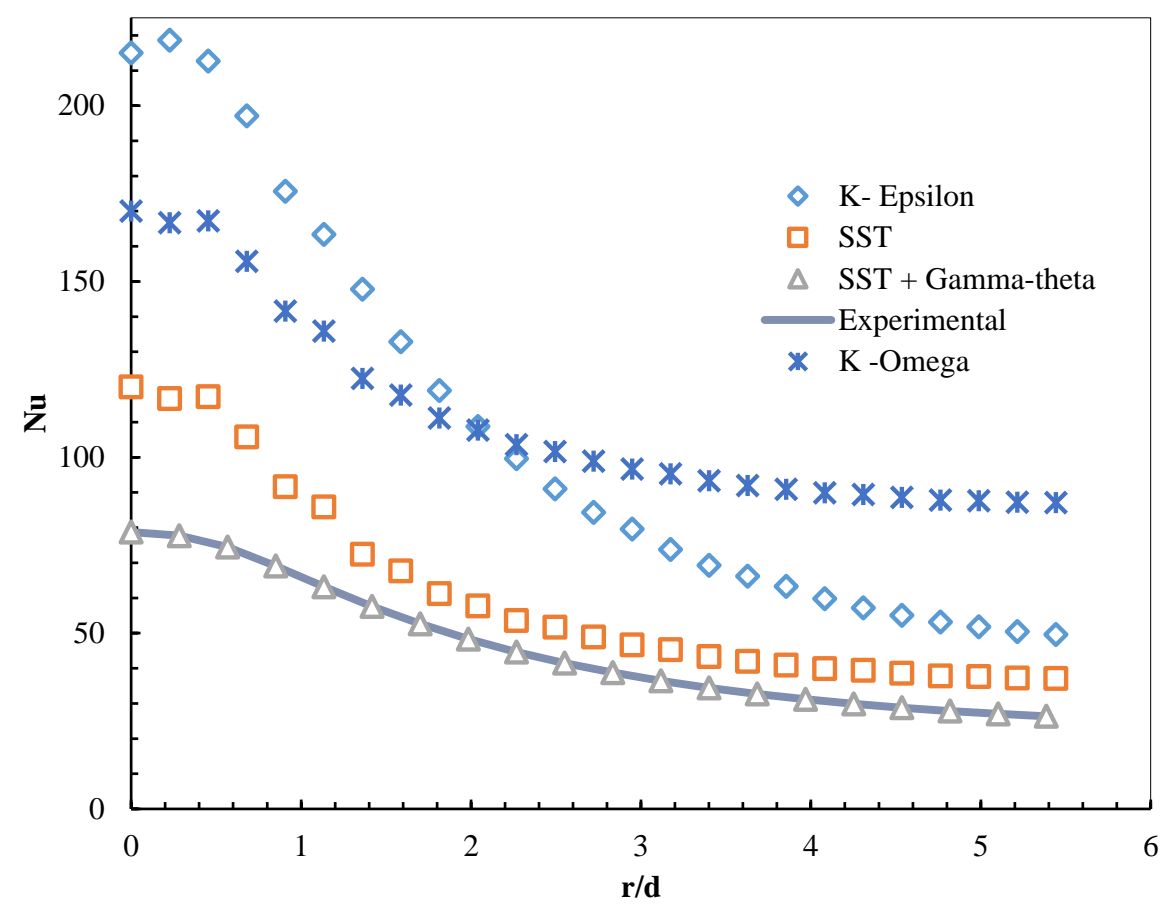

Fig. 4. Nusselt profile for different turbulence model at $\mathrm{Z} / \mathrm{d}=4, \mathrm{Re}=6000$

\section{Results}

\subsection{Arrival of Non-Uniformity Due to Variation in Re}

Figure 5 shows the variation in local Nusselt magnitude against $r / d$ at constant $z / d=4$. The Reynolds number is varied in $1000,2000,27000,36000$, and 45000 . The Nusselt profile is smooth up to $\operatorname{Re}<27000$, and at $\operatorname{Re}=27000$, non-uniform variation emerges in the Nusselt profile. As Reynold's number is increased, i.e., $\operatorname{Re}>27000$, non-uniformity in the Nusselt profile goes on increasing. Thus, at $R e=27000$ and $Z / d=4$ i.e. at $C=6750$ the profile becomes non-uniform and for $C<6750$ it is smooth. Velocity contours show the transition in velocity and the cause of non-uniformity, as shown in Figure 7.

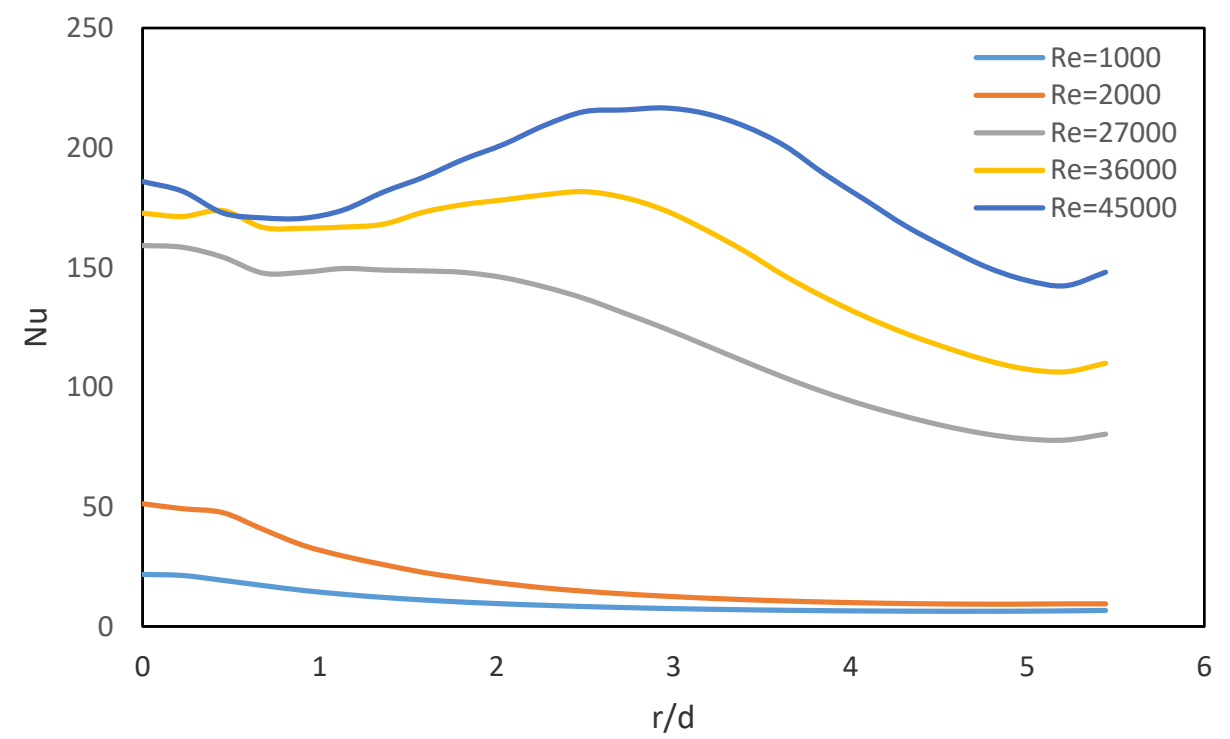

Fig. 5. Nusselt profile at $\operatorname{Re}=1000,2000,27000,36000,45000$ and $Z / d=4$ 


\subsection{Arrival of Non-Uniformity Due to Variation in Z/D}

Figure 6 shows the local Nusselt magnitude variation versus the $\mathrm{r} / \mathrm{d}$ ratio. The profile is obtained at constant $\mathrm{Re}=6000$ and by varying $\mathrm{Z} / \mathrm{d}=0.5,0.6,0.75,1$ and 1.5 . The smoothness exists till $\mathrm{Z} / \mathrm{d}>$ 0.75 , and at $Z / d=0.75$, roughness starts occurring in the Nusselt profile. At $Z / d<0.75$, roughness magnitude increases as $Z / d$ is reduced. Thus, at $R e=6000$ and $Z / d=0.75$, i.e., $C=8000$ is evaluated to be the critical value at which roughness occurs in the Nusselt profile.

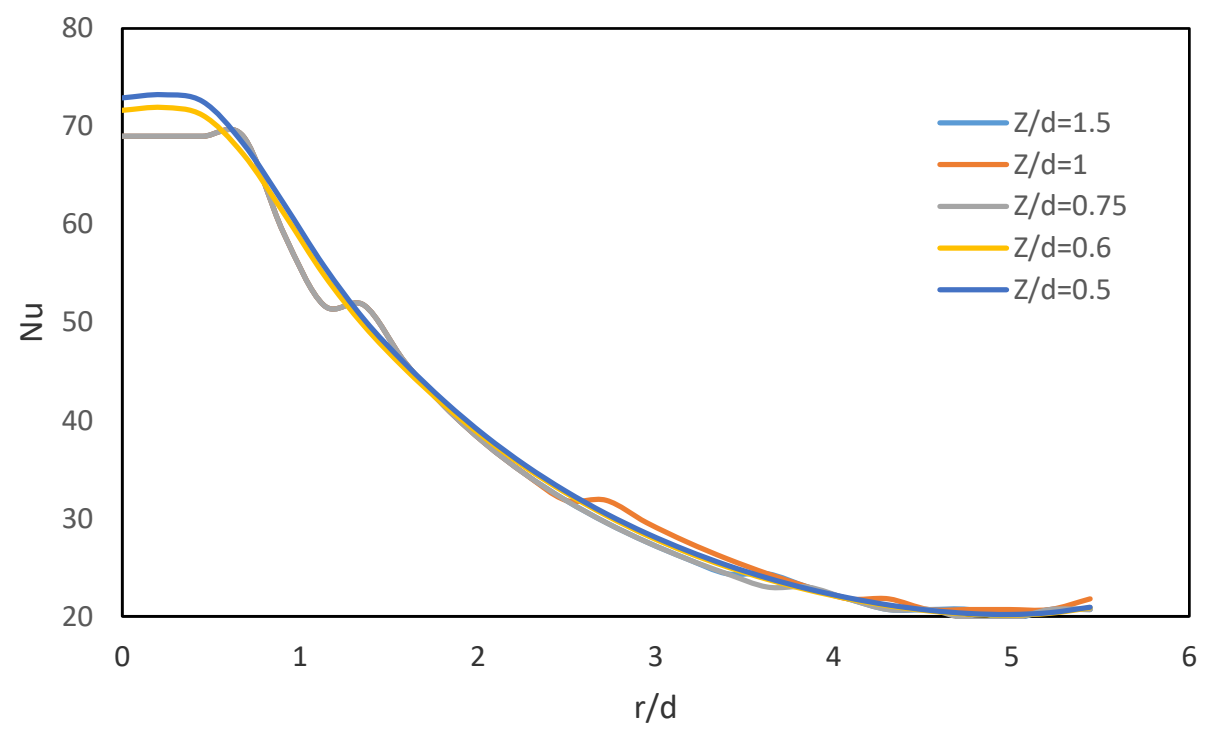

Fig. 6. Nusselt profile at $Z / d=0.5,0.6,0.75,1,1.5$ and $\operatorname{Re}=6000$

3.3 Non-Dimensional Constant Representing the Arrival of Non-Uniformity in Nusselt Profile and Its Validation

The magnitude of constant with variation in Reynolds number at constant $\mathrm{Z} / \mathrm{d}$ is calculated to be 6750 , and with the change in $\mathrm{Z} / \mathrm{d}$ at a fixed $\mathrm{Re}=6000$, it is found to be 8000 . Therefore, it is concluded that the constant at which roughness appears in the Nusselt profile is 7400 . For $C<7400$, the Nusselt profile is smooth, and for $C>7400$, it is rough. The non-dimensional constant $C$ is verified with previous literature in Table 1.

Table 1

Validation of non-dimensional constant ' $C$ ' with previous literature

\begin{tabular}{lllll}
\hline Authors & $\begin{array}{l}\text { Reynolds } \\
\text { number }\end{array}$ & Z/d & C & $\begin{array}{l}\text { Nature of } \\
\text { Nusselt Profile }\end{array}$ \\
\hline Yuling et al., [19] & 11000 & 13 & 846 & Smooth \\
Katti and Prabhu [20] & 28000 & 4 & 7000 & Smooth \\
Jr-Ming et al., [21] & 25100 & 2 & 12550 & Rough \\
Dahbia and Amina [22] & 10600 & 1 & 10600 & Rough \\
\hline
\end{tabular}

\subsection{Physical Justification for the Occurrence of Non-Uniformity}

Figure 7 shows the velocity contours at different values of $C$. At $C<7400$ (Figure $7(a)$ ), the flow is not totally developed, and it hits the target before potential core, hence the Nusselt profile is smooth. At $C=7400$ (Figure $7(\mathrm{~b})$ ), the flow is totally developed, and it hits the target just at the potential core; 
hence the Nusselt profile is beginning to get rough. At $C>7400$ (Figure $7(c)$ ), the flow is totally developed, and it hits the target long after reaching the potential core; hence the Nusselt profile is rough. Thus, the velocity reaching potential core plays a vital role in the nature of the Nusselt profile.

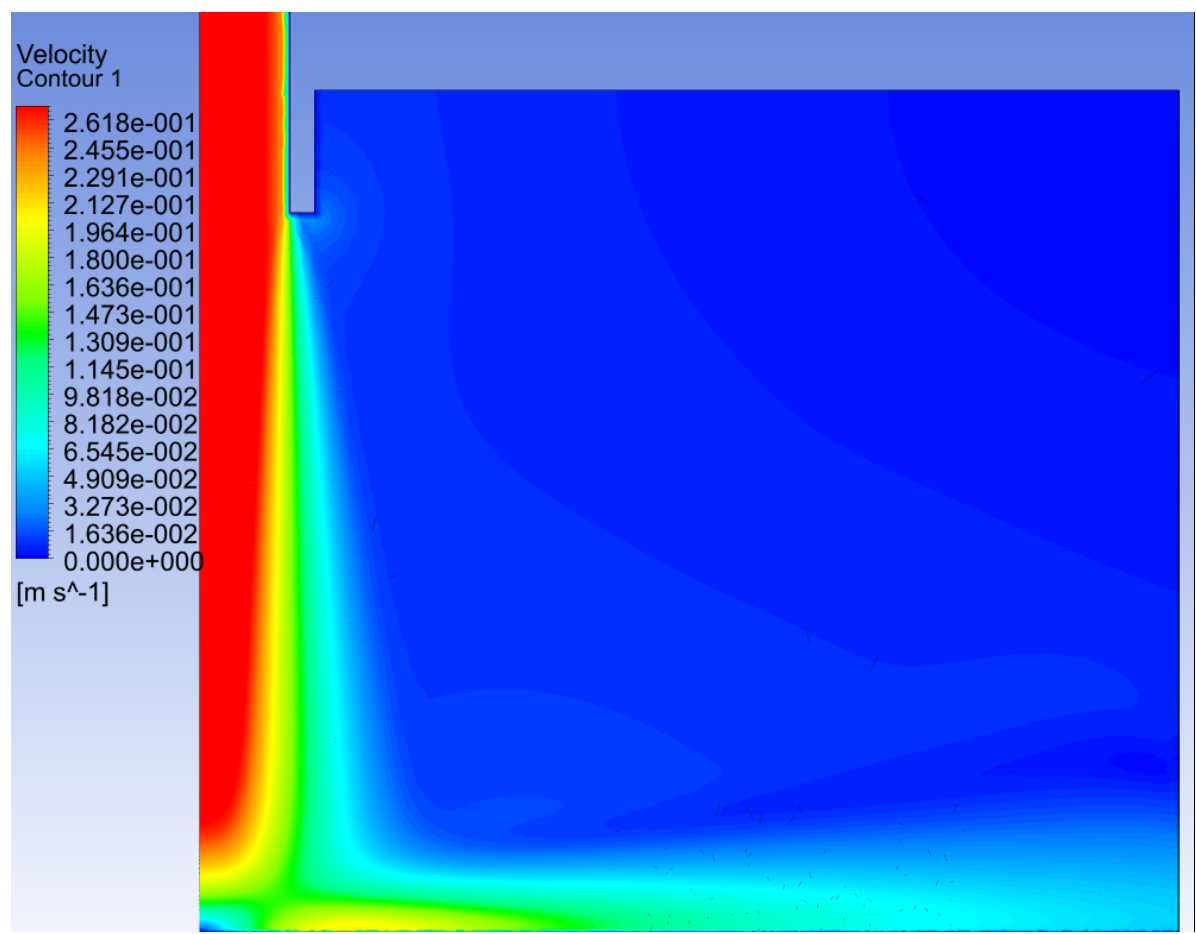

(a) $\mathrm{C}<7400$

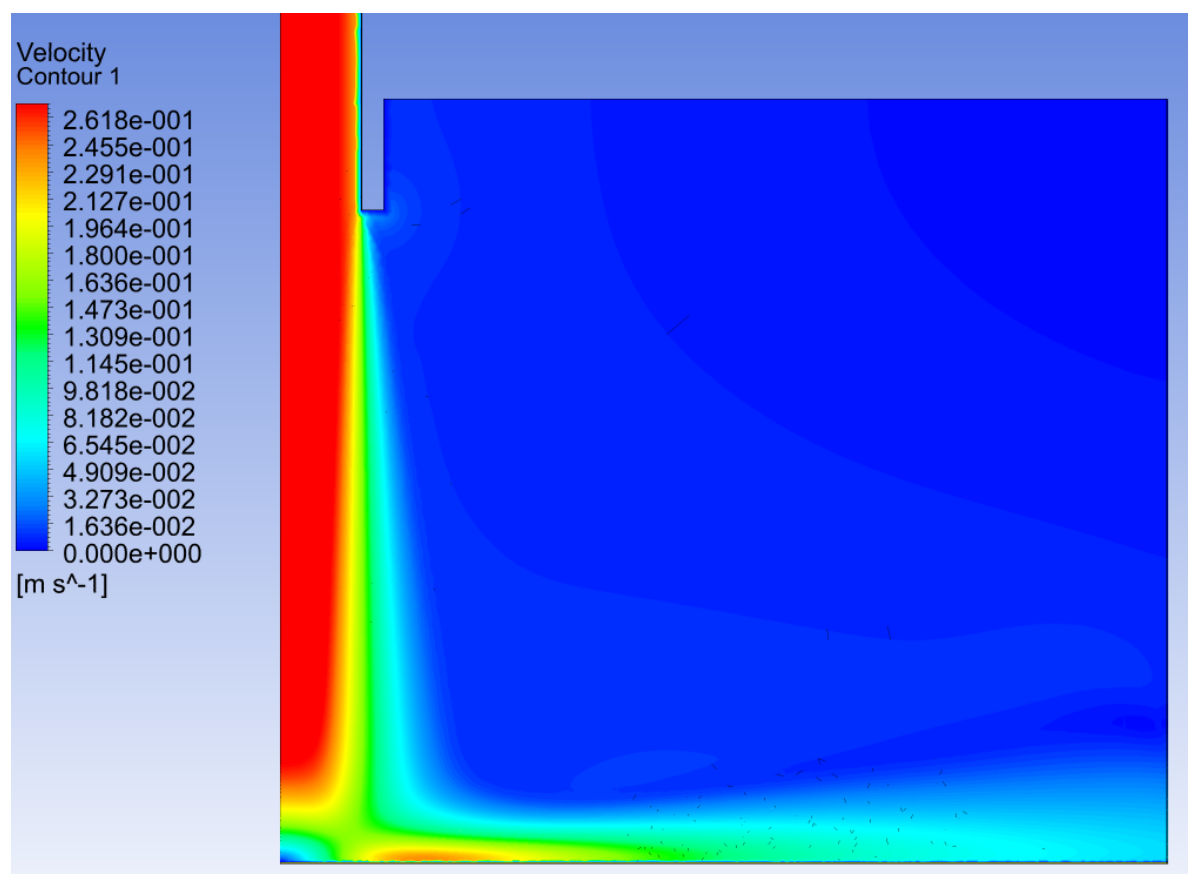

(b) $C=7400$ 


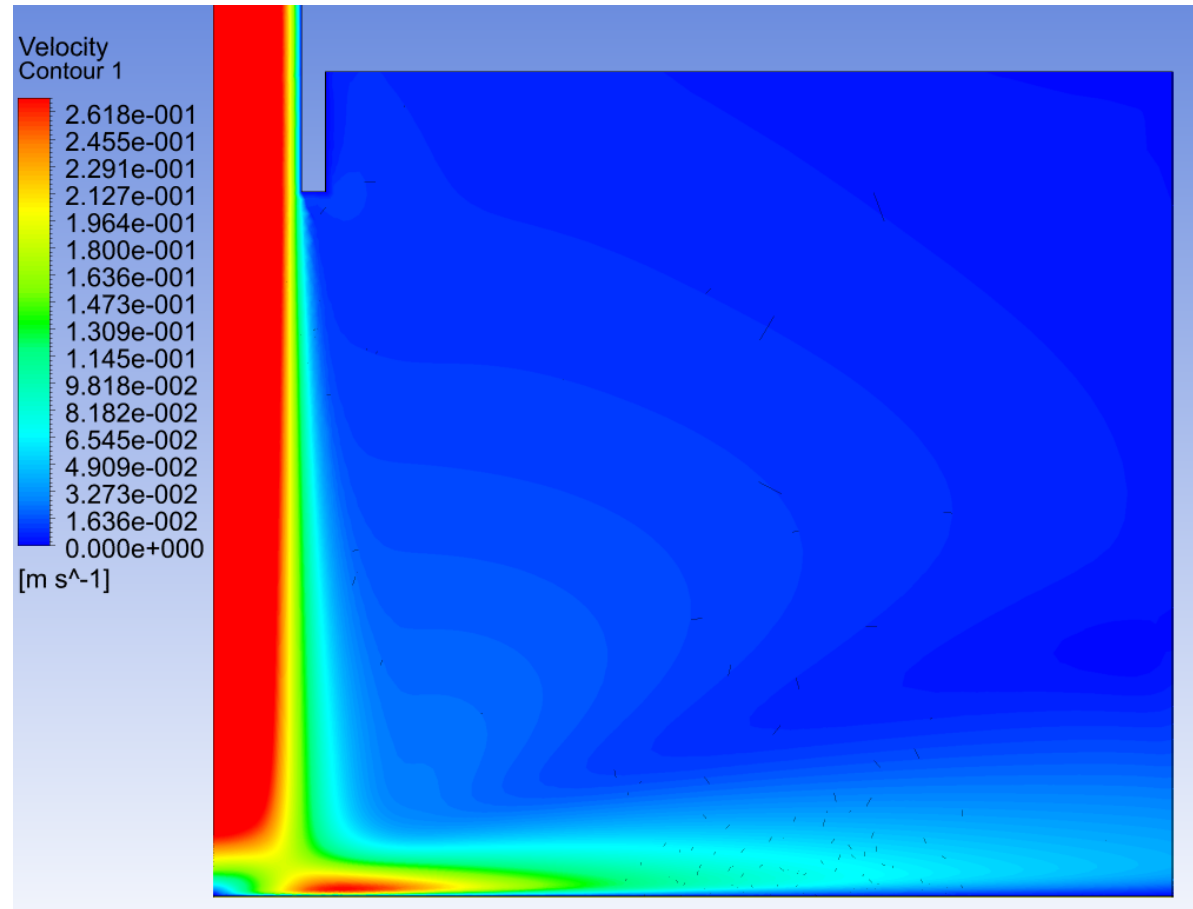

(c) $C>7400$

Fig. 7. Velocity Contours at a different value of $C$

\section{Conclusions}

The value of constant $\mathrm{C}$ above which the Nusselt profile becomes non-uniform is found out to be 7400. As the value of the constant reaches above 7400, the pattern becomes non-uniform and secondary peaks appear, which leads to a sudden temperature rise at some locations. Also, a computational model is designed, which predicts accurate results with a grid having a growth rate of 1.025 , and SST + Gamma-Theta model is concluded to be useful for turbulence modelling. For the future work perspective, in order to implement compute intensive modelling, Map-Reduce algorithm could be considered to be used at the back-end for optimized scheduling to get enhanced execution of ANSYS [26].

\section{Acknowledgement}

The authors would like to acknowledge the RUI grant (RUI 1001/PAERO/8014035) and RU Top-Down grant (1001/PAERO/870052) provided by the Research Creativity and Management Office, Universiti Saint Malaysia to support this research.

\section{References}

[1] Umair, S. Mohd, and N. Parashram Gulhane. "Numerical investigation of non-dimensional constant representing the occurrence of secondary peaks in the Nusselt profile curve." International Journal of Engineering TRANSACTIONS A 29 (2016): 1453-1461.

https://doi.org/10.5829/idosi.ije.2016.29.10a.14

[2] Umair, Siddique Mohd, and Nitin Parashram Gulhane. "On numerical investigation of heat transfer augmentation through pin fin heat sink by laterally impinging air jet." Procedia Engineering 157 (2016): 89-97.

https://doi.org/10.1016/i.proeng.2016.08.342

[3] Umair, Siddique Mohd, and Nitin Parashram Gulhane. "On numerical investigation of non-uniformity in cooling characteristic for different materials of target surfaces being exposed to impingement of air jet." International Journal of Modeling, Simulation, and Scientific Computing 8, no. 03 (2017): 1750024.

https://doi.org/10.1142/s1793962317500246 
[4] Umair, Siddique Mohammed, Abhijeet Rangnath Kolawale, Ganesh Anurath Bhise, and Nitin Parashram Gulhane. "On numerical heat transfer characteristic study of flat surface subjected to variation in geometric thickness." International Journal of Computational Materials Science and Engineering 6, no. 2 (2017): 1750010. https://doi.org/10.1142/s2047684117500105

[5] Siddique, Umair M., Ganesh A. Bhise, and Nitin P. Gulhane. "On numerical investigation of local Nusselt profile between flat surface and impinging air jet from straight circular nozzle and power law correlations generation." Heat Transfer-Asian Research 47, no. 1 (2018): 126-149.

https://doi.org/10.1002/htj.21295

[6] Umair, Siddique Mohammed, Abdulrahman Alrobaian, Sher Afghan Khan, Marthande Gnanagonda Kashinath, and Patil Rajesh. "Numerical Investigation of Critical Range for the Occurrence of Secondary Peaks in the Nusselt Distribution Curve." CFD letters 10, no. 2 (2018): 1-17.

[7] Siddique, Umair M., Gulhane P. Nitin, Sher A. Khan, Jan Taler, Arthur Cebula, Pawel Oclon, and Rajesh Patil. "Numerical investigation of semiempirical relations representing the local Nusselt number magnitude of a pin fin heat sink." Heat Transfer-Asian Research 48, no. 5 (2019): 1857-1888.

https://doi.org/10.1002/htj.21460

[8] Mohd Umair, S., N. P. Gulhane, A. R. A. Al-Robaian, and S. A. Khan. "On Numerical Investigation of Semi-empirical Relations Representing Local Nusselt Number at Lower Nozzle-target Spacing's." International Journal of Engineering 32, no. 1 (2019): 137-145. https://doi.org/10.5829/ije.2019.32.01a.18

[9] Umair, Siddique Mohd, Sher Afghan Khan, Abdulrahman Alrobaian, and Emaad Ansari. "Numerical study of heat transfer augmentation using pulse jet impinging on pin fin heat sink." CFD Letters 11, no. 3 (2019): 84-91.

[10] Khan, Sher Afghan, Abdulrahman A. Alrobaian, Mohammed Asadullah, and Aswin. "Threaded spikes for bluff body base flow control." Journal of advanced research in fluid mechanics and thermal sciences 53, no. 2 (2019): 194-203.

[11] Khan, Sher Afghan, Abdulrahman Abdulla Al Robaian, Mohammed Asadullah, and Abdul Mohsin Khan. "Grooved cavity as a passive controller behind backward facing step." Journal of Advanced Research in Fluid Mechanics and Thermal Sciences 53, no. 2 (2019): 185-193.

[12] Pathan, Khizar Ahmed, Prakash S. Dabeer, and Sher Afghan Khan. "Investigation of base pressure variations in internal and external suddenly expanded flows using CFD analysis." CFD Letters 11, no. 4 (2019): 32-40.

[13] Pathan, Khizar Ahmed, Prakash S. Dabeer, and Sher Afghan Khan. "Influence of Expansion Level on Base Pressure and Reattachment Length." CFD Letters 11, no. 5 (2019): 22-36.

[14] Sajali, Muhammad Fahmi Mohd, Abdul Aabid, Sher Afghan Khan, Fharukh Ahmed Ghasi Mehaboobali, and Erwin Sulaeman. "Numerical investigation of flow field of a non-circular cylinder." CFD Letters 11, no. 5 (2019): 37-49.

[15] Khan, Sher Afghan, Abdul Aabid, Fharukh Ahmed Mehaboobali Ghasi, Abdulrahman Abdullah Al-Robaian, and Ali Sulaiman Alsagri. "Analysis of area ratio in a CD nozzle with suddenly expanded duct using CFD method." CFD Letters 11, no. 5 (2019): 61-71.

[16] Akhtar, Mohammad Nishat, Elmi Abu Bakar, Abdul Aabid, and Sher Afghan Khan. "Effects of Micro jets on the Flow Field of the Duct with Sudden Expansion." International Journal of Innovative Technology and Exploring Engineering (IJITEE) 8, no. 9 S2 (2019): 636-640. https://doi.org/10.35940/ijitee.i1129.0789s219

[17] Akhtar, Mohammad Nishat, Elmi Abu Bakar, Abdul Aabid, and Sher Afghan Khan. "Control of CD Nozzle Flow Using Microjets at Mach 2.1." International Journal of Innovative Technology and Exploring Engineering (IJITEE) 8, no. 9 S2 (2019): 631-635.

https://doi.org/10.35940/ijitee.i1128.0789s219

[18] Khan, Ambareen, Nurul Musfirah Mazlan, Mohd Azmi Ismail, and Mohammad Nishat Akhtar. "Experimental and Numerical Simulations at Sonic and Supersonic Mach Numbers for Area Ratio 7.84." CFD Letters 11, no. 5 (2019): 50-60.

[19] Shi, Yuling, M. B. Ray, and A. S. Mujumdar. "Computational study of impingement heat transfer under a turbulent slot jet." Industrial \& Engineering Chemistry Research 41, no. 18 (2002): 4643-4651. https://doi.org/10.1021/ie020120a

[20] Katti, Vadiraj, and S. V. Prabhu. "Experimental study and theoretical analysis of local heat transfer distribution between a smooth flat surface and impinging air jet from a circular, straight pipe nozzle." International Journal of Heat and Mass Transfer 51, no. 17-18 (2008): 4480-4495. https://doi.org/10.1016/i.ijheatmasstransfer.2007.12.024

[21] Miao, Jr-Ming, Chen-Yuan Wu, and Ping-Hei Chen. "Numerical investigation of confined multiple-jet impingement cooling over a flat plate at different crossflow orientations." Numerical Heat Transfer, Part A: Applications 55, no. 11 (2009): 1019-1050.

https://doi.org/10.1080/10407780903014335 
[22] Benmouhoub, Dahbia, and Amina Mataoui. "Turbulent heat transfer from a slot jet impinging on a flat plate." Journal of heat transfer 135, no. 10 (2013): 102201.

https://doi.org/10.1115/1.4024554

[23] Siddique Mohd, Umair, Emaad Ansari, Sher Afghan Khan, Nitin Parashram Gulhane, and Rajesh Patil. "Numerical Investigation of Nondimensional Constant and Empirical Relation Representing Nusselt Profile Nonuniformity." Journal of Thermophysics and Heat Transfer 34, no. 1 (2020): 215-229.

https://doi.org/10.2514/1.t5828

[24] Siddique, Umair, Emaad Ansari, Sher Afghan Khan, and Rajesh Patil. "Numerical Investigation of Secondary Peaks in Nusselt Profile Under Water Jet Impingement." Journal of Thermophysics and Heat Transfer 34, no. 2 (2020): 18.

https://doi.org/10.2514/1.t5905

[25] Siddique, Umair, Emaad Ansari, Sher Afghan Khan, and Rajesh Patil. "Numerical Investigation of Semi-Empirical Relation Representing Nusselt Number Under Waterjet Impingement." Journal of Thermophysics and Heat Transfer (2020).

https://doi.org/10.2514/1.t5947

[26] Mohammad Nishat Akhtar, Junita Mohamad Saleh, Habib Awais, Elmi Abu Bakar. "Map-Reduce based tipping point scheduler for parallel image processing." Expert Systems With Applications 139 (2020): 112848.

https://doi.org/10.1016/j.eswa.2019.112848 